\title{
Telomere length correlates with histopathogenesis according to the germinal center in mature B-cell lymphoproliferative disorders
}

\author{
Marco Ladetto, Mara Compagno, Irene Ricca, Marco Pagano, Alberto Rocci, Monica Astolfi, Daniela Drandi, Paola Francia di Celle, \\ Maria Dell'Aquila, Barbara Mantoan, Sonia Vallet, Gloria Pagliano, Federica De Marco, Roberto Francese, Loredana Santo, \\ Alessandra Cuttica, Carlo Marinone, Mario Boccadoro, and Corrado Tarella
}

In this study we investigated telomere restriction fragment (TRF) length in a panel of mature B-cell lymphoproliferative disorders (MBCLDs) and correlated this parameter with histology and histopathogenesis in relation to the germinal center (GC). We assessed 123 MBCLD samples containing $\mathbf{8 0} \%$ or more tumor cells. TRF length was evaluated by Southern blot analysis using a chemiluminescence-based assay. GC status was assessed through screening for stable and ongoing somatic mutations within the immunoglobulin heavy-chain genes. Me- dian TRF length was 6170 bp (range, 1896-11 $200 \mathrm{bp}$ ) and did not correlate with patient age or sex. TRF length was greater in diffuse large cell lymphoma, Burkitt lymphoma, and follicular lymphoma (medians: 7789 bp, 9471 bp, and 7383 bp, respectively) than in mantle cell lymphoma and chronic lymphocytic leukemia (medians: 3582 bp and 4346 bp, respectively). GC-derived MBCLDs had the longest telomeres, whereas those arising from GC-inexperienced cells had the shortest $\left(P<10^{-9}\right)$. We conclude that (1) TRF length in MBCLD is highly heteroge- neous; (2) GC-derived tumors have long telomeres, suggesting that minimal telomere erosion occurs during GC-derived lymphomagenesis; and (3) the short TRF lengths of GC-inexperienced MBCLDs indicates that these neoplasms are good candidates for treatment with telomerase inhibitors, a class of molecules currently the subject of extensive preclinical evaluation. (Blood. 2004;103:4644-4649)

(c) 2004 by The American Society of Hematology

\section{Introduction}

Telomeres are repeated DNA sequences at the ends of chromosomes in eukaryotic cells, and they play a critical role in maintaining chromosomal stability. ${ }^{1-6}$ In most somatic cells, they shorten at each mitotic division as a result of the inability of DNA polymerase to synthesize open extremities of DNA. ${ }^{2-7}$ As the number of divisions increases, telomere restriction fragment (TRF) length falls beyond a critical value, leading to senescence, a peculiar phase of cell life mostly characterized by growth inhibition. ${ }^{8-10}$ Senescence is distinguished by low proliferative activity and is regarded as an important checkpoint in somatic cell life. If the senescence checkpoint is bypassed (eg, through p53 + Rb1 inactivation), cells continue to divide until they reach a second proliferative barrier named crisis. Crisis is associated with genetic instability, chromosomal fusions, and a high tendency toward apoptosis and malignant transformation. ${ }^{11-13}$

The telomeres of germinal cells are preserved from shortening by an enzymatic RNA-containing complex called telomerase, whose catalytic subunit (h-TERT) has intrinsic reverse transcriptase capability and adds repeated DNA sequences to chromosomal ends. ${ }^{114-18}$ Telomerase is usually not expressed in somatic cells, with few exceptions characterized by high replicative potential. ${ }^{15-18}$ In addition, telomerase activity (TA) is often turned off during differentiation, even in cell subtypes in which there is significant h-TERT activity during early development. ${ }^{16,17}$ This is probably related to the limited proliferative potential of terminally differentiated cells. B cells are a notable exception to this rule. Naive B cells have no detectable TA, whereas strong telomerase activation is observed in germinal center (GC)-derived B cells. This is probably related to the high mitotic activity of GC cells. ${ }^{19}$ In post-GC maturation, increased TA is still observed in some subtypes, but its level is lower than during GC maturation. ${ }^{19}$ This peculiar aspect of $\mathrm{B}$-cell development is reflected by TRF length in normal B cells. No GC erosion occurs in GC B cells despite proliferative activity that is among the highest ever observed in human cells. ${ }^{19}$

During tumorigenesis, telomeres usually undergo progressive shortening until TA is restored to allow indefinite cell replication. $^{20,21}$ This late activation is now regarded as a critical step in tumor development, and telomerase is considered to play a crucial role in sustaining neoplastic cell survival. ${ }^{1,21-23}$ This explains why most tumors are characterized by short telomeres despite the presence of high TA levels. This peculiar feature of cancer cells has suggested that telomerase inhibition could be a good approach to slow down cancer replication and ultimately to induce selective cancer cell death. ${ }^{1,24-26}$
From the Divisione di Ematologia, Dipartimento di Medicina ed Oncologia Sperimentale, and the Divisione di Anatomia Patologica, Dipartimento di Scienze Biomediche ed Oncologia Umana, Università di Torino, Azienda Ospedaliera S. Giovanni Battista, Turin; and the Divisione di Medicina Generale VII, Azienda Ospedaliera S. Giovanni Battista, Turin, Italy.

Submitted December 30, 2003; accepted February 9, 2004. Prepublished online as Blood First Edition Paper, February 26, 2004; DOI 10.1182/ blood-2003-12-4412.

Supported in part by Associazione Italiana Ricerca sul Cancro (Milan), Compagnia di San Paolo, (Turin), Consiglio Nazionale delle Ricerche, and
Ministero dell' Università e della Ricerca. B.M., M.C. Compagno, and D.D. are or were recipients of fellowships from Fondazione Angela Bossolasco (Turin). I.R. is the recipient of a fellowship from Fondazione Italiana Ricerca sul Cancro (Milan). M.D. is the recipient of a fellowship from Comitato Piemontese Luigi Ghirotti.

Reprints: Marco Ladetto, Cattedra di Ematologia, Via Genova 3, 10126 Torino, Italy; e-mail: marco.ladetto@unito.it.

The publication costs of this article were defrayed in part by page charge payment. Therefore, and solely to indicate this fact, this article is hereby marked "advertisement" in accordance with 18 U.S.C. section 1734

(C) 2004 by The American Society of Hematology 
In contrast to findings in solid tumors, few data have been accumulated on TRF lengths in mature B-cell lymphoproliferative disorders (MBCLDs). Studies have been primarily restricted to multiple myeloma ${ }^{27}$ and chronic lymphocytic leukemia, ${ }^{28,29}$ but TRF lengths in MBCLDs as a whole have not been quantified. The aim of this study was to determine TRF lengths in a large panel of mature B-cell tumors and to assess the link between TRF length and tumor histopathogenesis in relation to the GC. Patients were evaluated for TRF length and GC status (ie, pre-GC, GC-derived, and post-GC) according to the presence of stable or ongoing somatic mutations within the variable regions of immunoglobulin heavy-chain genes $\left(\mathrm{V}_{\mathrm{H}}\right)$.

\section{Patients, materials, and methods}

\section{Patient and sample characteristics}

One hundred twenty-three tumor samples from 117 patients with MBCLD of 7 subtypes, displaying $80 \%$ or more neoplastic infiltration by flow cytometry, were used. Twenty-two were from peripheral blood (PB), 44 from bone marrow (BM), and 57 from lymph nodes (LNs). Samples obtained from different tissues during the same disease phase were available for 6 patients (BM vs PB in 2 patients, BM vs LN in 3 patients, and PB vs $L N$ in 1 patient). Diagnoses was made in accordance with World Health Organization (WHO) classification. ${ }^{30}$ Our panel consisted of 9 patients with mantle cell lymphoma (MCL), 31 with chronic lymphocytic leukemia (CLL), 31 with follicular lymphoma (FL), 5 with Burkitt lymphoma (BL), 14 with diffuse large-cell lymphoma (DLCL), 9 with marginal zone lymphoma (MZL), and 18 with multiple myeloma (MM) (with PB features of plasma cell leukemia [PCL] in 6). All diagnoses were established by the same hemopathologist, who was unaware of the TRF length results when defining the subtypes. Diagnosis was always supported by histology and flow cytometry. Immunohistochemistry, cytogenetics, and molecular biology analyses were also performed, if required, according to the WHO criteria. ${ }^{30}$ Samples were taken at diagnosis in 80 patients and after treatment in 37 patients. Samples taken after treatment were obtained at true relapse (occurring after a previous complete or very good partial remission) in 20 patients and during disease progression or stable disease in 7. Ten CLL patients were partial responders still displaying more than $80 \%$ tumor contamination in BM or PB (partial response was defined according to Cheson et $\mathrm{al}^{31}$ as a 50\% reduction in PB lymphocytes, with total resolution of BM failure if present). Patient demographic and clinical characteristics are shown in Table 1.

\section{Cell line and DNA extraction}

The MM cell line KMS-11 (kindly provided by Massimo Massaia, University of Turin, Italy), which has a TRF length of $3420 \mathrm{bp}$, was used for dilution tests against PB mononuclear cells from a healthy donor. BM and PB mononuclear cells were separated by Ficoll-Hypaque density gradient centrifugation. Lymph node tissue was always obtained from fresh or frozen samples. Genomic DNA was extracted using the DNAzol reagent (Gibco BRL Life Technologies, Grand Island, NY) according to the manufacturer's recommendations.

\section{Determination of TRF length}

TRF length was determined using Southern blot analysis according to the following procedure. Aliquots of $2 \mu \mathrm{g}$ DNA were digested by mixing HinfI (20 MU) and RsaI (20 MU) (Roche Diagnostics, Mannheim, Germany) for 2 hours at $37^{\circ} \mathrm{C}$, according to the manufacturer's recommendations. TRF were then separated by $0.8 \%$ agarose gel electrophoresis in $1 \times$ TAE buffer ( $\mathrm{pH}$ 8.0). Gels were transferred to a positively charged nylon membrane (catalog no. 1417 240; Roche Diagnostics) and were ultraviolet (UV) light cross-linked for 10 minutes. Hybridization was performed with the TeloTAGG Telomere Length Assay Kit (Roche Diagnostics), which contains all the reagents required. Membranes were prehybridized for 2 hours in the prehybridization solution at $62^{\circ} \mathrm{C}$ and then hybridized for 3 hours in the same conditions by adding $2 \mu \mathrm{L}$ of the digoxigenin (DIG)-labeled telomere-specific probe. After hybridization, filters were washed twice at room temperature for 15 minutes in $2 \times$ washing solution and then twice at $39 \mathrm{C}^{\circ}$ in $0.5 \times$ washing solution for 20 minutes. Filters were then incubated with a DIG-specific antibody covalently coupled to alkaline phosphatase (AP). Finally, results were visualized using AP metabolizing CDP-Star, a highly sensitive chemiluminescent substrate. The light signal produced on the site of the hybridized probe was recorded on x-ray film (Lumi-Film Chemiluminescent Detection Film; Roche Diagnostics). Each assay was performed twice. Membranes were then scanned and analyzed with Kodak Digital Science 1D Image Analysis Software (Scientific Imaging Systems, New Haven, CT). Two different parameters were calculated for each telomere smear. The first was mean TRF length, calculated as already described. ${ }^{7,32,33}$ The second was peak TRF length, the point of maximum signal intensity defining the highest concentration of telomere repeats. These 2 parameters were assessed to minimize any bias associated with contaminating nonneoplastic cells. Percentages were always $20 \%$ or less and were thus not expected to influence the peak values, whereas they could have influenced the extremities of the smear, thus potentially biasing calculation of mean TRF length.

\section{$V_{H}$ sequencing analysis}

Tumor-specific $\mathrm{V}_{\mathrm{H}}$ rearrangements were amplified starting from genomic DNA or, for MM and PCL only, from immunoglobulin-specific cDNA as previously described. ${ }^{34-36}$ Primers and PCR conditions for $\mathrm{V}_{\mathrm{H}}$ amplification have been previously described. ${ }^{34,37}$ Briefly, $1 \mu \mathrm{g}$ genomic DNA or $2 \mu \mathrm{L}$ cDNA were amplified using 3 sets of consensus forward primers, 2 derived from the framework region 1 (FR1) and 1 from the leader region, together with a J consensus region antisense primer. ${ }^{34,37}$ The reaction was carried out for 30 to 33 cycles with denaturation at $94^{\circ} \mathrm{C}$ for 1 minute, annealing at $62^{\circ} \mathrm{C}$ for 30 seconds, and extension at $72^{\circ} \mathrm{C}$ for 30 seconds, with a final extension of 10 minutes at $72^{\circ} \mathrm{C}$. PCR products were then analyzed by electrophoresis on $2 \%$ agarose gels. When an apparently clonal PCR product was observed, the sample of interest was reamplified on a large scale for direct sequencing of the tumor immunoglobulin $\mathrm{H}(\mathrm{IgH})$ rearrangement. Purification of polymerase chain reaction (PCR) products, direct

Table 1. Characteristics of samples and patients

\begin{tabular}{|c|c|c|c|c|c|c|c|c|c|c|c|c|c|}
\hline \multirow[b]{3}{*}{ Histology } & \multirow{3}{*}{$\begin{array}{c}\text { No. } \\
\text { samples* }\end{array}$} & \multirow{2}{*}{\multicolumn{3}{|c|}{ Sample type, no. }} & \multirow{3}{*}{$\begin{array}{c}\text { No. } \\
\text { patients* }\end{array}$} & \multirow{2}{*}{\multicolumn{2}{|c|}{ Sex, no. }} & \multicolumn{4}{|c|}{ Age } & \multirow{2}{*}{\multicolumn{2}{|c|}{ Clinical status }} \\
\hline & & & & & & & & \multirow{2}{*}{$\begin{array}{l}\text { Younger } \\
\text { than } 30 \mathrm{y}\end{array}$} & \multirow[b]{2}{*}{$30-49 y$} & \multirow[b]{2}{*}{$50-69$ y } & \multirow{2}{*}{$\begin{array}{c}\text { Older } \\
\text { than } 70 y\end{array}$} & & \\
\hline & & LN & BM & PB & & M & $\mathbf{F}$ & & & & & Diagnosis & After treatment \\
\hline CLL & 34 & 7 & 10 & 17 & 31 & 20 & 11 & 0 & 5 & 21 & 5 & 13 & 18 \\
\hline $\mathrm{MCL}$ & 10 & 9 & 1 & 0 & 9 & 7 & 2 & 0 & 0 & 5 & 4 & 9 & 0 \\
\hline $\mathrm{FL}$ & 33 & 19 & 13 & 1 & 31 & 20 & 11 & 1 & 8 & 18 & 4 & 12 & 19 \\
\hline $\mathrm{BL}$ & 5 & 2 & 3 & 0 & 5 & 4 & 1 & 1 & 2 & 2 & 0 & 5 & 0 \\
\hline DLCL & 14 & 13 & 1 & 0 & 14 & 7 & 7 & 1 & 2 & 7 & 4 & 14 & 0 \\
\hline MZL & 9 & 7 & 0 & 2 & 9 & 5 & 4 & 0 & 2 & 3 & 4 & 9 & 0 \\
\hline $\mathrm{MM}$ & 18 & 0 & 16 & 2 & 18 & 11 & 7 & 0 & 3 & 10 & 5 & 18 & 0 \\
\hline Total & 123 & 57 & 44 & 22 & 117 & 74 & 43 & 3 & 22 & 66 & 26 & 80 & 37 \\
\hline
\end{tabular}

*For 2 patients with FL, 3 with CLL, and 1 with MCL, 2 different tissues obtained during the same treatment phase were available. 
sequencing reactions, and sequence analysis were performed as previously described. ${ }^{36,37}$

\section{$V_{H}$ analysis for somatic mutations}

Mutation analysis of the $\mathrm{V}_{\mathrm{H}}$ region was then performed as follows: nucleotide sequences were aligned to the V-Base sequence directory (MRC Centre for Protein Engineering, Cambridge, United Kingdom) (http:// www.mrc-cpe.cam.ac.uk/vbase-ok.php?menu = 901). Percentage of homology was calculated by counting the number of mutations between the $5^{\prime}$ end of FR1 and the $3^{\prime}$ end of FR3, as previously described. ${ }^{38}$ Sequences with $2 \%$ or less deviation from any germline $\mathrm{V}_{\mathrm{H}}$ sequence were considered unmutated and, thus, as belonging to GC-inexperienced cells. Sequences containing more than $2 \%$ deviation from any known germline $\mathrm{V}_{\mathrm{H}}$ were considered mutated and were defined as GC experienced. Patients failing $\mathrm{V}_{\mathrm{H}}$ sequencing were excluded from further analysis. ${ }^{38}$

\section{Evaluation of the presence of ongoing SHM}

The presence of the ongoing somatic hypermutation (SHM) mechanism was evaluated in all samples, defined as GC-experienced MBCLD to distinguish GC-derived from post-GC-derived MBCLD. Clonal $\mathrm{V}_{\mathrm{H}}$ rearrangements were amplified with appropriate primers and cloned into the pCR4-TOPO plasmid vector (Invitrogen, Paisley, United Kingdom). Twenty or more randomly chosen bacterial clones were expanded into LB medium overnight. Three milliliters culture medium was purified with Wizard Plus Minipreps DNA Purification System (Promega). Plasmids were then sequenced by IRBM (Servizio Sequenziamento Automatico, Pomezia, Roma, Italy). Only clones with identical or nearly identical CDR3 were considered. Substitution mutations observed in only 1 clone and in more than 1 clone were classed as unconfirmed and confirmed mutations, respectively. ${ }^{39}$ Only confirmed mutations were considered evidence of ongoing SHM; unconfirmed mutations were disregarded. ${ }^{40-42}$

\section{Results}

\section{Validation of the modified strategy for the calculation of peak TRF length}

Because the patient samples were not purified, we had concerns about the potential confounding role of contaminating nonneoplastic cells on calculations of peak TRF length. To validate our strategy, dilution tests with the KMS-11 cell line were performed. Cancer cells were diluted on a background of PB mononuclear cells from a healthy donor (50-year-old man). The dilution test was performed by calculating peak TRF length on samples containing tumor cells in $5 \%$ increments from $50 \%$ to $100 \%$. The same experiment was performed 3 times. For the purposes of this study, TRF measurements were considered acceptable if those of the contaminated cell samples were $5 \%$ or less different from those in the sample containing $100 \%$ tumor cells. Peak TRF of samples containing $5 \%, 10 \%, 15 \%, 20 \%, 25 \%, 30 \%, 35 \%$, and $40 \%$ contaminating cells showed median increases in peak TRF length, respectively, of $1.5 \%, 2.0 \%, 2.3 \%, 3.0 \%, 3.8 \%, 4.6 \%, 8 \%$, and $16 \%$. Samples containing $45 \%$ and $50 \%$ contaminating cells showed a bimodal aspect with 2 peaks of similar size, as would be expected from cell populations containing similar amounts of cancer cells and healthy cells. Based on these results, peak TRF values were close enough to the expected rate up to contamination of $30 \%$ nonneoplastic cells. In contrast, mean TRF length was acceptable only up to a contamination of $20 \%$ (data not shown). Thus, both approaches were appropriate for TRF length calculation in our panel, though peak TRF values were more accurate.

\section{TRF lengths in the whole MBCLD population}

The mean value of peak TRF length in our population was $6170 \mathrm{bp}$. The population was heterogeneous, with a standard deviation of \pm 1985 bp. Median TRF length was 6060 bp (range, 1896$11200 \mathrm{bp}$ ). The 10th, 25th, 75th, and 90th percentiles were 3334, 5100,7755 , and $8725 \mathrm{bp}$, respectively. A representative example of TRF length analysis is shown in Figure 1. Demographic features were not predictive of TRF length. In particular, TRF length of MBCLD samples was not associated with patient age when the entire population was considered $\left(r^{2}=0.0783\right)$ (data not shown). In addition, when analysis was performed separately on each disease subtype, we did not observe higher TRF lengths in young patients than in older ones (data not shown). Similarly, sex had no influence on TRF length (data not shown). No significant differences in TRF lengths were apparent between samples taken at diagnosis and those taken after treatment of the 2 disorders (FL and CLL) in which samples from treated patients were available (CLL at diagnosis: median peak TRF length, $5102 \mathrm{bp}$; range, 2162-8211 bp; CLL after treatment median peak TRF length, 4120 bp; range, 2253-7900 bp; $P=.94$ ) (FL at diagnosis: median peak TRF length, 7367 bp; range, 5355-8725 bp; FL after treatment median peak TRF length, $7475 \mathrm{bp}$; range, $4361-10030 \mathrm{bp} ; P=.95)$. In 6 patients TRF length was assessed on different tissues, but always with identical results (Figure 1; patient C1437).

\section{TRF length according to histology}

Remarkable differences in peak TRF length were observed between the histologic subtypes (Figure 2). Patients with FL, BL, and DLCL had the highest values, and their median and range values were 7383 bp (range, 4361-10 030 bp), 9471 bp (range, 705211200 bp), and 7789 bp (range, 5244-10 304 bp), respectively. In

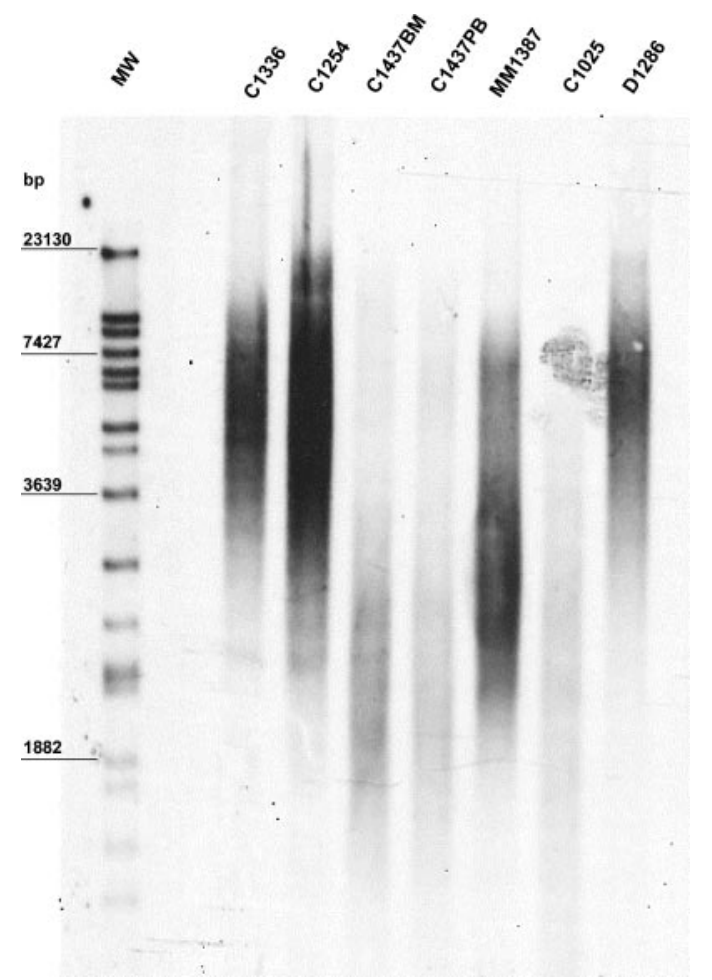

Figure 1. Representative example of TRF length in 6 MBCLD patients. Peak TRF lengths are expressed as base pairs (bp). MW indicates molecular-weight ladder; $\mathrm{BM}$, bone marrow; PB, peripheral blood. C1336 and C1254 are CLL patients with mutated $\mathrm{V}_{\mathrm{H}} ; \mathrm{C} 1437$ and $\mathrm{C} 1025$ are CLL patients with unmutated $\mathrm{V}_{\mathrm{H}}(\mathrm{C} 1437$ includes C1437BM and C1437PB); MM1387 is a MM patient; D1286 is a DLCL patient. 


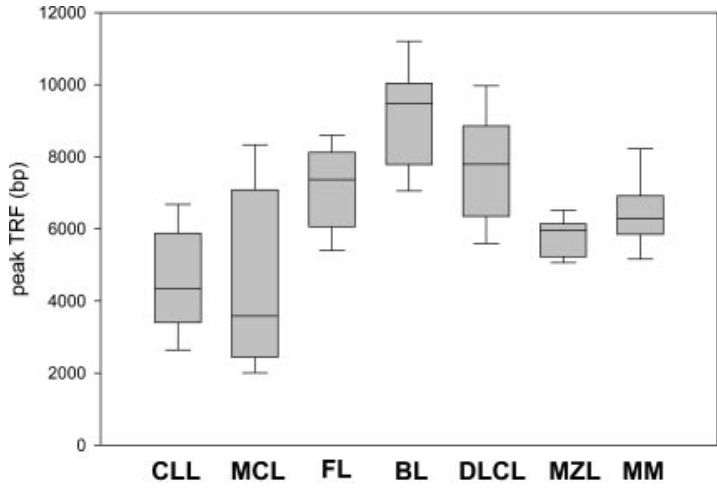

Figure 2. Peak TRF length according to MBCLD histotype. There are marked differences between the subtypes. Box plots indicate 25 th percentile, median value and 75th percentile (horizontal lines of rectangle from the bottom, respectively) and 10th and 90th percentiles (horizontal lines outside rectangle).

contrast, MCL and CLL patients had short telomeres, often close to the critical threshold of senescence. Their median and range values were 3582 bp (range, 1896-8961 bp) and 4346 bp (range, 2094$8211 \mathrm{bp}$ ), respectively. MZL and MM displayed intermediate TRF lengths: 5969 bp (range, 5058-6681 bp) and 6283 bp (range, 4917-8900 bp). The telomeres of aggressive lymphomas were not shorter than those of indolent subtypes. When indolent lymphomas, namely those with overall survival longer than 3 years when treated conventionally (CLL, FL, MZL), were compared with aggressive subtypes (median survival less than 3 years with conventional treatment) (BL, DLCL, MCL), a modest trend toward greater TRF length was noted for the aggressive subtypes $(P=.03)$ (data not shown).

\section{TRF length according to GC experience}

Given that several histologic subtypes (including MCL, CLL, DLCL, and MZL) are highly heterogeneous in terms of GC experience of cell of origin, we looked for associations between GC status and significant differences in TRF length. The presence of stable and ongoing somatic mutations in the $\mathrm{V}_{\mathrm{H}}$ genes of all patients was determined, as shown in Figure $3 . \mathrm{V}_{\mathrm{H}}$ sequencing was successful in 100 of the 117 (85\%) patients. Patients for whom $V_{H}$ sequencing failed were excluded from further evaluation. Patients showing homology greater than $98 \%$ to any known $\mathrm{V}_{\mathrm{H}}$ sequence were classified as GC inexperienced. Seventy-two (72\%) patients defined as GC experienced underwent further cloning to assess the

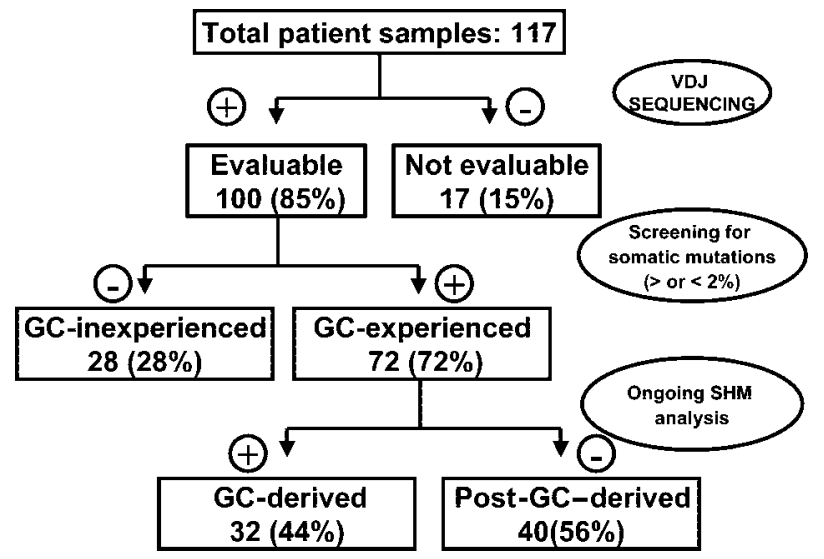

Figure 3. Experimental strategy for defining histopathogenesis of samples according to GC origin.

presence of ongoing SHM and were subsequently classified as GC derived (ongoing SHM-positive) or post-GC derived (ongoing SHM-negative). Figure 4 indicates how subtypes were classified according to mutational status. TRF length according to mutational status is represented in Figure 5. GC-inexperienced tumors were compared with GC-experienced tumors (Figure 5A). GC-inexperienced tumors had shorter telomeres than GC-experienced tumors $\left(P=10^{-10}\right)$. GC-experienced tumors were further divided into GC-derived and post-GC-derived tumors (Figure 5B). GC-derived tumors had greater peak TRF lengths than GC-inexperienced $\left(P<10^{-9}\right)$ and post-GC-derived tumors $(P=.004)$. In addition, post-GC-derived tumors appeared to have longer TRFs than pre-GC MBCLD $\left(P<10^{-6}\right)$. As expected, TRF length was also associated with mutational status in CLL patients. Telomeres were significantly longer in the $\mathrm{V}_{\mathrm{H}^{-}}$mutated subtype $\left(P<10^{-4}\right)$ (Figure 5C). Of note, the association between TRF length and GC status existed when only patients at diagnosis were considered (GC experienced vs GC inexperienced $\left[P<10^{-7}\right]$; pre-GC vs GCderived $\left[P<10^{-5}\right]$; pre-GC vs post-GC $\left[P<10^{-3}\right]$; GC-derived vs post-GC-derived $[P<.05$; data not shown]). The relationship between disease aggressiveness and TRF length was assessed within both subgroups, and no difference was noticed (indolent pre-GC-derived vs aggressive pre-GC-derived; $P=.71$; indolent GC-derived vs aggressive GC-derived; $P=.11$; indolent post-GCderived vs aggressive post-GC-derived; $P=.13$ ). Results were similar when mean rather than peak TRF lengths were considered (data not shown).

\section{Discussion}

This study is the first comprehensive evaluation of TRF length in all the most frequent histologic MBCLD subtypes. TRF length was found to be highly heterogeneous among different subtypes of MBCLD. FL, DLCL, and BL have long telomeres (median peak TRF length, $7580 \mathrm{bp}$ ), whereas MCL and CLL have short telomeres (median peak TRF length, $4116 \mathrm{bp}$ ) that are often close to the critical threshold of senescence. Our main finding is that a high peak TRF length is typical of lymphomas arising from the GC as

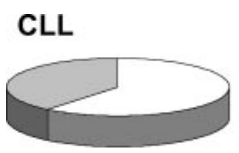

FL

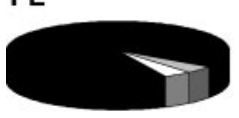

DLCL

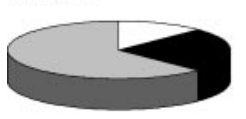

MM

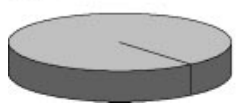

Figure 4. Classification according to GC experience of MBCLD subtypes. White, black, and gray sections represent the percentages of GC-inexperienced tumors, GC-derived tumors, and post-GC-derived tumors, respectively. 


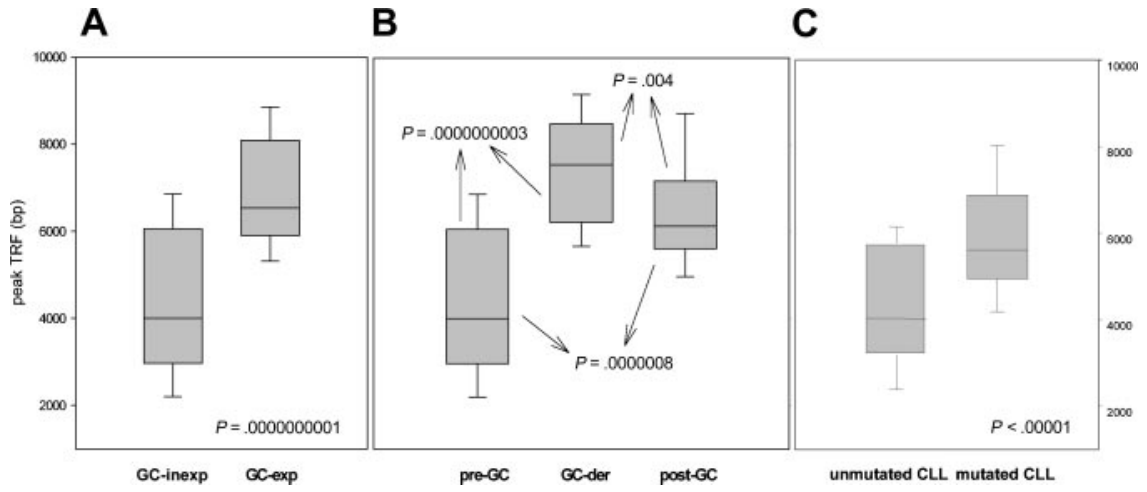

opposed to other MBCLD, particularly those arising from GCinexperienced cells. This suggests that GC-derived lymphomagenesis occurs in the absence of the marked telomeric loss often associated with neoplastic transformation.

Telomere status has been extensively investigated in solid tumors, but few reports have addressed the same issue in MBCLD, and none have comprehensively investigated it in a large panel of MBCLD, including the most important entities in the WHO lymphoma classification. ${ }^{20-22,30}$ Some studies have looked at CLL and MM. ${ }^{27-29}$ Bechter et $\mathrm{al}^{28}$ investigated TRF length in $58 \mathrm{CLL}$ patients and found that long telomeres are associated with favorable clinical features and better survival. ${ }^{28}$ In $\mathrm{MM}, \mathrm{Wu}$ et $\mathrm{al}^{27}$ observed that samples displaying reduced TRF lengths have worse outcomes. It has been concluded that short telomeres are mainly a consequence of increased proliferative activity, usually observed in patients with more aggressive disease. However, the association between short telomeres and worse outcomes in CLL is largely explained by the fact that patients with poor-prognosis, $\mathrm{V}_{\mathrm{H}^{-}}$ unmutated, GC-inexperienced CLL cells have shorter telomeres than patients with $\mathrm{V}_{\mathrm{H}}$-mutated CLL, as clearly shown in the recent papers by Damle et $\mathrm{al}^{29}$ and Hultdin et al. ${ }^{43}$ Our results conclusively demonstrate that the most important feature influencing telomere length in MBCLD is tumor histopathogenesis, with particular respect to GC experience. They also point to a minor role for high-proliferative activity as a basic determinant of TRF length in MBCLD. The peak TRF length of indolent histotypes, in fact, was no greater than that of aggressive histotypes, and the telomeres of highly proliferating MBCLDs, namely BL and DLCL, were longer than those of slowly proliferating disorders, such as CLL. Of note, no difference in TRF length could be associated with disease aggressiveness when MBCLDs characterized by similar histopathogenesis were compared. However, a different proliferative activity may explain TRF differences within a well-defined histopathologic entity, as suggested by $\mathrm{Wu}$ et $\mathrm{al}^{27}$ for MM.

The mean TRF length of GC-derived normal B cells is slightly (fewer than $1000 \mathrm{bp}$ in 4 of 5 patients), though consistently, greater than that of naive B cells. ${ }^{19}$ However, this does not explain the large difference (4000 bp) between their neoplastic counterparts. ${ }^{19,44}$ Comparing our results with those of Weng et al ${ }^{19}$ in normal B cells shows that GC lymphomagenesis is associated with an approximate telomeric loss of fewer than 2000 bp. In contrast, lymphomagenesis in GC-inexperienced B cells is associated with a loss of more than $4000 \mathrm{bp}$ and, hence, a TRF length close to the critical senescence threshold. The remarkable telomere preservation in GC-derived tumors should probably be attributed to the presence of high TA in the parent GC B cell, clearly demonstrated by Weng et al. ${ }^{19}$ However, the role of additional factors might be also important, in particular telomere-binding factors such as TRF1,
Figure 5. Peak TRF length according to GC experience. (A) Peak TRF length in GC-experienced and GC-inexperienced tumors, classified according to the presence or absence of somatic hypermutation. (B) GCexperienced tumors are divided into GC derived and post-GC-derived according to the presence or absence of ongoing somatic hypermutation. (C) How TRF length correlates with GC experience in CLL patients. Box plots indicate 25 th percentile, median value, and 75 th percentile (horizontal lines of rectangle from the bottom, respectively) and 10th and 90th percentiles (horizontal lines outside rectangle).
TRF2, and Pot 1. ${ }^{1}$ Because an effective telomere-preserving machinery is a basic step for neoplastic transformation, it can be speculated that during GC lymphomagenesis, one of the critical checkpoints that plays a protective role against neoplastic transformation is turned off "by default" because of the peculiar biologic features of GC-derived B cells. ${ }^{1,45}$ This feature, together with the heavy proliferative activity and the genetic instability associated with $\mathrm{V}_{\mathrm{H}}$ switching and ongoing SHM, may explain why GC-associated MBCLDs form the vast majority of human B-cell neoplasms.

TRF length in post-GC-derived tumors was intermediate between the 2 previously mentioned subgroups. Most samples show similar results of approximately $6000 \mathrm{bp}$. Post-GC-derived normal $\mathrm{B}$ cells have TRF lengths of approximately $8500 \mathrm{bp} .{ }^{19}$ Our findings indicate that telomeric loss in post-GC lymphomagenesis is approximately $2500 \mathrm{bp}$. This value is definitely lower than in GC-inexperienced cells. This difference can be explained by the presence of residual TA in parent post-GC cells and by more rapid restoration of TA during lymphomagenesis. The observation that memory B cells have low or no TA suggests that the second hypothesis is more reasonable, at least for CLL. Nevertheless, the remarkable TRF length homogeneity of post-GC MBCLD remains an intriguing finding. This subgroup is the most heterogeneous of the 3 because it includes patients with 6 different subtypes (all but BL) who have little in common biologically and clinically. However, despite such important differences, these tumors undergo a remarkably similar degree of telomere erosion during lymphomagenesis.

We studied 80 samples taken at diagnosis and 37 taken after treatment. We noticed no significant difference in terms of TRF length between the 2 subgroups, in seeming contradiction to a previous report by Remes et al, ${ }^{46}$ who observed significant telomeric differences when samples obtained at diagnosis were compared with those obtained at relapse. This apparent contradiction can probably be explained by 2 factors. First, in our panel, only a fraction of patients had true relapses, whereas several samples were obtained from partial responders and patients with progressive or stable disease. Second, our panel of treated patients had only indolent neoplasms, whereas the population described by Remes et $\mathrm{al}^{46}$ consisted mostly of patients with aggressive tumors. It is reasonable to speculate that significant variations in TRF length may occur after chemotherapy only in the presence of marked cytoreduction. This might allow the selection of specific tumor populations with TRF lengths different from those observed at diagnosis. Compared with those described by Remes et al, ${ }^{46}$ our patients underwent minor degrees of cytoreduction because of less chemosensitive disease and milder chemotherapy. This might 
explain why they displayed TRF lengths similar to those observed at diagnosis in patients with analogous tumors.

In addition to their biologic relevance to MBCLD pathogenesis, our findings are of clinical interest because telomerase is now regarded as one of the most promising targets for anticancer treatment. Antisense oligonucleotides and small molecules such as BIBR-1532 24-26,47 have been evaluated in vitro as anticancer agents for solid tumors, and they may soon become significant in the treatment of hematologic cancers. Telomerase inhibitors act through several mechanisms, including induction of pharmacologic senes- cence and triggering of apoptosis. ${ }^{26,47,48}$ Although the mechanism of telomerase inhibitors is probably not only telomere oriented, theoretical considerations and in vitro experiments indicate that their therapeutic effects will be particularly pronounced in the presence of short telomeres. Our results indicate that these agents may be particularly suitable for the treatment of MCL and $\mathrm{V}_{\mathrm{H}}$-unmutated CLL. In contrast, the long telomeres of FCL and DLCL cells might potentially protect cancer cells from pharmacologically induced senescence for a long time. At our laboratory we are performing in vitro cell line studies to verify this hypothesis.

\section{References}

1. Hahn WC. Role of telomeres and telomerase in the pathogenesis of human cancer. J Clin Oncol. 2003;21:2034-2043.

2. McEachern MJ, Krauskopf A, Blackburn EH. Telomeres and their control. Annu Rev Genet. 2000; 34:331-358

3. Moyzis RK, Buckingham JM, Cram LS, et al. A highly conserved repetitive DNA sequence, (TTAGGG)n, present at the telomeres of human chromosomes. Proc Natl Acad Sci U S A. 1988; 85:6622-6626.

4. Meyne J, Ratliff RL, Moyzis RK. Conservation of the human telomere sequence (TTAGGG) $n$ among vertebrates. Proc Natl Acad Sci U S A. 1989;86:7049-7053.

5. Allsopp RC, Vaziri H, Patterson C, et al. Telomere length predicts replicative capacity of human fibroblasts. Proc Natl Acad Sci U S A. 1992;89: 10114-10118.

6. Blasco MA, Lee HW, Hande MP, et al. Telomere shortening and tumor formation by mouse cells lacking telomerase RNA. Cell. 1997;91:25-34.

7. Harley CB, Futcher AB, Greider CW. Telomeres shorten during ageing of human fibroblasts. Nature. 1990;345:458-460.

8. Yu GL, Bradley JD, Attardi LD, et al. In vivo alteration of telomere sequences and senescence caused by mutated Tetrahymena telomerase RNAs. Nature. 1990;344:126-132.

9. Sedivy JM. Can ends justify the means? telomeres and the mechanisms of replicative senescence and immortalization in mammalian cells. Proc Natl Acad Sci U S A. 1997;95:9078-9081.

10. Hahn WC, Stewart SA, Brooks MW, et al. Inhibition of telomerase limits the growth of human cancer cells. Nat Med 1999; 5:1164-1170.

11. Shay JW, Wright WE. Quantitation of the frequency of immortalization of normal human diploid fibroblasts by SV40 large T-antigen. Exp Cell Res. 1989;184:109-118.

12. Wei W, Sedivy JM. Differentiation between senescence (M1) and crisis (M2) in human fibroblast cultures. Exp Cell Res. 1999;253:519-522.

13. Halvorsen TL, Leibowitz G, Levine F. Telomerase activity is sufficient to allow transformed cells to escape from crisis. Mol Cell Biol. 1999;19:18641870.

14. Ramakrishnan S, Sharma HW, Farris AD, et al Characterization of human telomerase complex. Proc Natl Acad Sci U S A. 1997;94:10075-10079.

15. Hiyama E, Hiyama K, Tatsumoto N, et al. Telomerase activity in human intestine. Int $\mathrm{J}$ Oncol. 1996;9:453-458

16. Yasumoto S, Kunimura C, Kikuchi K, et al. Telom erase activity in normal human epithelial cells. Oncogene. 1996;13:433-439.

17. Harle-Bachor C, Boukamp P. Telomerase activity in the regenerative basal layer of the epidermis in human skin and in immortal and carcinoma-derived skin keratinocytes. Proc Natl Acad Sci U S A. 1996;93:6476-6481.

18. Yui J, Chiu CP, Lansdorp PM. Telomerase activity in candidate stem cells from fetal liver and adult bone marrow. Blood. 1998;91:3255-3262.

19. Weng NO, Granger L, Hodes RJ. Telomere lengthening and telomerase activation during human B cell differentiation. Proc Natl Acad Sci U S A. 1997;94:10827-10832.

20. Butler MG, Sciadini M, Hedges LK, et al. Chromosome telomere integrity of human solid neoplasms. Cancer Genet Cytogenet. 1996;86: 50-53.

21. Djojosubroto MW, Choi YS, Lee HW, et al. Telomeres and telomerase in aging, regeneration and cancer. Mol Cells. 2003:15:164-175.

22. Kim NW, Piatyszek MA, Prowse KR, et al. Specific association of human telomerase activity with immortal cells and cancer. Science. 1994; 266:2011-2015.

23. Kim SH, Kaminker P, Campisi J. Telomeres, aging and cancer: in search of a happy ending. Oncogene. 2002;21:503-511.

24. Klaus D, Ulrike H, Pilar G-C, et al. A highly selec tive telomerase inhibitor limiting human cancer cell proliferation. EMBO J. 2001;20:6958-6968.

25. Pascolo E, Wenz C, Lingner J, et al. Mechanism of human telomerase inhibition by BIBR1532, a synthetic, non-nucleosidic drug candidate. J Biol Chem. 2002;277:15566-15572.

26. Saretzki G. Telomerase inhibition as cancer therapy. Cancer Lett. 2003;194:209-219.

27. Wu KD, Orme LM, Shaughnessy J, et al. Telomerase and telomere length in multiple myeloma: correlations with disease heterogeneity, cytogenetic status, and overall survival. Blood. 2003; 101:4982- 4989

28. Bechter OE, Eisterer W, Pall G, et al. Telomere length and telomerase activity predict survival in patients with B cell chronic lymphocytic leukemia. Cancer Res. 1998;58:4918-4922.

29. Damle RN, Batliwalla FM, Ghiotto F, et al. Telomere length and telomerase activity delineate distinctive replicative features of the B-CLL subgroups defined by lg $\mathrm{V}$ gene mutations. Blood. 2003 [Epub ahead of print].

30. Harris NL, Jaffe ES, Diebold J, et al. World Health Organization classification of neoplastic diseases of the hematopoietic and lymphoid tissues: report of the Clinical Advisory Committee meeting-Airlie House, Virginia, November 1997. J Clin Oncol. 1999;17:3835-3849.

31. Cheson BD, Bennett JM, Grever M, et al. National Cancer Institute-sponsored Working Group guidelines for chronic lymphocytic leukemia: revised guidelines for diagnosis and treatment. Blood. 1996; 87:4990-4997.

32. Harley CB. Telomeres and aging. In: Telomeres. Cold Spring Harbor, NY: Cold Spring Harbor Laboratory; 1995.

33. Lansdorp PM, Verwoerd NP, van de Rijke FM, et al. Heterogeneity in telomere length of human chromosomes. Hum Mol Genet. 1996;5:685-691.

34. Ladetto M, Donovan JW, Harig S, et al. Real-time polymerase chain reaction of immunoglobulin rearrangements for quantitative evaluation of minimal residual disease in multiple myeloma. Biol Blood Marrow Transplant. 2000;6:241-253.

35. Donovan JW, Ladetto M, Zou G, et al. Immunoglobulin heavy-chain consensus probes for realtime PCR quantification of residual disease in acute lymphoblastic leukemia. Blood. 2000;95: 2651-2658.

36. Ladetto $\mathrm{M}$, Omede $\mathrm{P}$, Sametti S, et al. Real-time polymerase chain reaction in multiple myeloma: quantitative analysis of tumor contamination of stem cell harvests. Exp Hematol. 2002;30:529536.

37. Voena C, Ladetto M, Astolfi M, et al. A novel nested-PCR strategy for the detection of rearranged immunoglobulin heavy-chain genes in $\mathrm{B}$ cell tumors. Leukemia. 1997;11:1793-1798.

38. Hamblin TJ, Orchard JA, Ibbotson RE, et al. CD38 expression and immunoglobulin variable region mutations are independent prognostic variables in chronic lymphocytic leukemia, but CD38 expression may vary during the course of the disease. Blood. 2002;99:1023-1029.

39. Gaidano G, Pasqualucci L, Capello D, et al. Aberrant somatic hypermutation in multiple subtypes of AIDS-associated non-Hodgkin lymphoma. Blood. 2003;102:1833-1841.

40. Capello D, Cerri M, Muti G, et al. Molecular histogenesis of posttransplant lymphoproliferative disorders. Blood. 2003 [Epub ahead of print].

41. Lossos IS, Alizadeh AA, Eisen MB, et al. Ongoing immunoglobulin somatic mutation in germinal center B cell-like but not in activated B cell-like diffuse large cell lymphomas. Proc Natl Acad Sci U S A. 2000;97:10209-10213.

42. Oeschger S, Bräuninger A, Küppers R, et al. Tumor cell dissemination in follicular lymphoma. Blood. 2002;99:2192-2198.

43. Hultdin M, Rosenquist R, Thunberg $U$, et al. Association between telomere length and $\mathrm{V}(\mathrm{H})$ gene mutation status in chronic lymphocytic leukaemia: clinical and biological implications. Br J Cancer. 2003;88:593-598.

44. Norrback KF, Hultdin M, Dahlenborg K, et al. Telomerase regulation and telomere dynamics in germinal centers. Eur J Haematol. 2001; 67:309317.

45. MacKenzie KL, Franco S, Naiyer AJ, et al. Multiple stages of malignant transformation of human endothelial cells modelled by co-expression of telomerase reverse transcriptase, SV40 T antigen and oncogenic N-ras. Oncogene. 2002;21:42004211.

46. Remes K, Norrback KF, Rosenquist R, et al. Telomere length and telomerase activity in malignant lymphomas at diagnosis and relapse. $\mathrm{Br} \mathrm{J}$ Cancer. 2000;82:601-607.

47. Damm K, Hemmann U, Garin-Chesa P, et al. A highly selective telomerase inhibitor limiting human cancer cell proliferation. EMBO J. 2001;20: 6958-6968.

48. Nakajima A, Tauchi T, Sashida G, et al. Telomerase inhibition enhances apoptosis in human acute leukemia cells: possibility of antitelomerase therapy. Leukemia. 2003;17:560-567. 


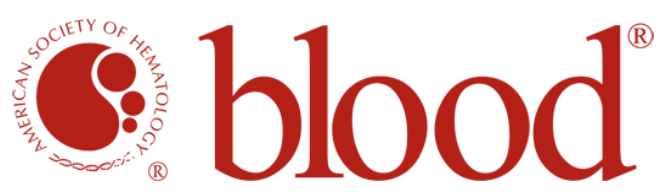

2004 103: 4644-4649

doi:10.1182/blood-2003-12-4412 originally published online February 26, 2004

\section{Telomere length correlates with histopathogenesis according to the germinal center in mature B-cell lymphoproliferative disorders}

Marco Ladetto, Mara Compagno, Irene Ricca, Marco Pagano, Alberto Rocci, Monica Astolfi, Daniela Drandi, Paola Francia di Celle, Maria Dell'Aquila, Barbara Mantoan, Sonia Vallet, Gloria Pagliano, Federica De Marco, Roberto Francese, Loredana Santo, Alessandra Cuttica, Carlo Marinone, Mario Boccadoro and Corrado Tarella

Updated information and services can be found at:

http://www.bloodjournal.org/content/103/12/4644.full.html

Articles on similar topics can be found in the following Blood collections

Clinical Trials and Observations (4987 articles)

Neoplasia (4182 articles)

Information about reproducing this article in parts or in its entirety may be found online at:

http://www.bloodjournal.org/site/misc/rights.xhtml\#repub_requests

Information about ordering reprints may be found online at:

http://www.bloodjournal.org/site/misc/rights.xhtml\#reprints

Information about subscriptions and ASH membership may be found online at:

http://www.bloodjournal.org/site/subscriptions/index.xhtml

Blood (print ISSN 0006-4971, online ISSN 1528-0020), is published weekly by the American Society of Hematology, 2021 L St, NW, Suite 900, Washington DC 20036.

Copyright 2011 by The American Society of Hematology; all rights reserved. 